\title{
The Association between Regular Use of Ridesourcing and Walking Mode Choice in Cairo and Tehran
}

\author{
Hamid Mostofi ${ }^{1, *} \mathbb{0}$, Houshmand Masoumi ${ }^{2,3}$ (1) and Hans-Liudger Dienel ${ }^{1}$ \\ 1 Mobility Research Cluster, Department of Work, Technology and Participation, Technische Universität Berlin, \\ 10587 Berlin, Germany; hans-liudger.dienel@tu-berlin.de \\ 2 Center for Technology and Society, Technische Universität Berlin, 10623 Berlin, Germany; \\ masoumi@ztg.tu-berlin.de \\ 3 Department of Transport and Supply Chain Management, College of Business and Economics, \\ University of Johannesburg, Johannesburg 2006, South Africa \\ * Correspondence: mostofidarbani@tu-berlin.de
}

Received: 31 May 2020; Accepted: 7 July 2020; Published: 13 July 2020

check for updates

\begin{abstract}
The rapid adoption of ridesourcing poses challenges for researchers and policymakers in the Middle East and North Africa (MENA), as it is an evolving new transport mode, and there is little research explaining its effects on mobility behaviors in this region. There is a concern that ridesourcing, which offers convenient and relatively cheap door to door services, encourages citizens to replace their sustainable travel modes, like walking, with car use. This effect has been studied relatively well in metropolises of the West, but less in the MENA agglomerations. This paper investigates whether regular use of ridesourcing impacts the walking mode choice in Cairo and Tehran. The analysis uses the results of 4926 face-to-face interviews in these two cities to compare the preference for using a vehicle instead of walking between regular users of ridesourcing and other motorized modes, including public bus, urban transit rails, private car, and traditional taxi. The findings indicate that in Cairo, the regular ridesourcing users are more likely than regular users of public transport to use a vehicle instead of walking inside their neighborhood. However, in both cities, ridesourcing users are less likely than regular private car users to replace walking by using vehicles.
\end{abstract}

Keywords: ridesourcing in the MENA region; walking mode choice; modal shift; the impact of ridesourcing on the nonmotorized mode

\section{Introduction}

In the information age, the influence of Information and Communication Technology (ICT) on mobility behavior, particularly on walking mode choice, is gaining increasing importance by changing the concept of distance, increased online connectivity and associated changes in individual lifestyles [1-5]. Many studies emphasize that nonmotorized transport modes are sustainable, safe, and efficient in terms of health, energy consumption and minimize environmental pollution [6-9], as well as improve the sustainable economy and social aspects [10-12]. However, with the emergence of smart mobility modes like ridesourcing in cities of the global south, it is necessary to study their impacts on the tendency of their regular users towards walking. As defined by the Society of Automotive Engineers (SAE International) for terms related to shared mobility, ridesourcing services are prearranged and on-demand transportation services in which drivers and passengers connect via digital applications to provide door-to-door mobility services like "Snapp" in Tehran, and "Careem" in Cairo [13]. Rayle et al. defined this new mobility service as ridesourcing because passengers can "source" a ride from a driver pool, including private passenger vehicles through smartphone apps. These apps communicate a passenger's location to a driver through GPS and charge a distance-based 
fare [3]. "Uber" company mentioned that Egypt is its biggest market in the MENA region (the Middle East and North Africa), including four million users and 157,000 drivers in 2017 [14]. In Iran, "Snapp" is the first Iranian ridesourcing company which started providing services in 2014, and had a ride increase of 70\% per month in Tehran, with 120,000 active drivers and 0.5 million users in 2016 [15,16]. This rapid growth indicates the potential impact of these new travel modes on travel behaviors in Cairo and Tehran. Some researchers mention the potential impact of ridesharing and ridesourcing on urban traffic congestion by changing the car ownership rate in the context of the global north [17-20]. However, there is a concern that ridesourcing, which offers relatively cheaper door to door services than private cars or traditional taxis, encourages citizens to replace their sustainable travel modes, like walking, by car. Rayle et al. (2015) conducted an intercept survey of ridesourcing users in San Francisco, indicating that around $40 \%$ of the ridesourcing trips replaced modes, such as public transit, and walking [4]. The average trip distance by online ride-hailing services is between two and four miles in five American cities [21], which confirms the potential impacts of this mode on walking mode choice. The impact of ridesourcing on other mobility modes depends on the type of service availability, type of urban design, and user characteristics [5,22]. For example, Alemi et al. (2018) reported that the younger generation (millennials) reduced their amount of walking/biking more than the older generations by ridesourcing adaptation [23].

This paper aims to study the association between the regular use of ridesourcing and the tendency to a modal shift from walking to motorized modes for near destinations in two cities of the MENA region (Cairo and Tehran). Tehran and Cairo are the megacities, located in the same region. With a large-scale look to the world regions, the countries located in the MENA region have a relatively similar culture, religion, climate, etc. In other words, these factors are different from, e.g., South America or South East Asia. The MENA region has been the geographical basis of many international studies like the ones done by the World Bank or the United Nations. Moreover, the ridesourcing companies started their activities in these two cities in the same year and got a remarkable share of the market in 2017. Furthermore, these two cities are representative of two different clusters of large cities in the MENA region in terms of population density, socioeconomic parameters, and public transport conditions which are mentioned in other studies, such as Reference [24]. For the above reasons, these two cities have been brought into this research. This study is based on the theory that the regular use of one transport mode influences other transport mode choices [25]. The research asks whether regular users of the different motorized modes, including ridesourcing, private cars, public transport and traditional taxis show significant differences in preference regarding replacing walking by vehicles for near destinations. The analysis uses the results of a large face-to-face survey in Tehran and Cairo in 2017 to compare the preference for modal shift from walking. For this comparison, the respondents are categorized based on their main motorized modes for their trips outside the neighborhood (far distance). Then we compare the preference of modal shift from walking between frequent users of ridesourcing and other motorized modes. We employ descriptive statistics and binary logistic regression models separately for Tehran and Cairo.

\section{Materials and Methods}

\subsection{Survey Design}

This analysis is based on the data of 4926 face-to-face interviews in summer and spring 2017 in Cairo and Tehran. The interviews were conducted in 12 neighborhoods (six for each city) from different land-use types in different parts of the city, including old town, in-between (transitional) urban forms, and areas that are newly developed parts in the last 30-40 years. The full details of the survey have already been published [26]. According to the literature review, the mode choice of walking is mostly affected by socioeconomic characteristics and road network quality of the neighborhood [27-30]. Therefore, the socioeconomic variables in this survey include gender, age, occupation, monthly household income and cost, and having a driving license. Economic variables 
of the survey, such as monthly household income and living costs, were asked in the currency of Iran and Egypt. Then the values have been converted to Euro, according to the exchange rate of the central banks in these countries in 2017. Due to the important role of the road network parameters in the tendency toward walking [29,31-34], two variables are defined in this survey as the connectivity indicators of the neighborhoods, which are:

1. Intersection density (nodes/ha): This indicator quantifies the number of intersections per unit area in a $600 \mathrm{~m}$-catchment area of each respondent's homes. Intersection density corresponds closely to block size in a neighborhood [29]. The greater intersection density indicates the smaller blocks, which means shorter walking distances and increases connectivity in the neighborhood.

2. Link node ratio (\%): The number of links (street segments) divided by nodes (street intersections) of the street network within the $600 \mathrm{~m}$-catchment area (based on the network) of each respondents' home. The greater link node ratio shows better connectivity of the neighborhoods. This indicator shows how many paths are in the network per each node as different possible directions for walking. However, this indicator is unrelated to the size or spacing of the blocks or intersections in the neighborhoods [30].

In the mobility section of the survey, the respondents were asked about their main mobility mode for their non-work trips outside the neighborhood. The respondents had to select only one option as their main mode. Out of 4926 interviews in both cities, 4388 responded that their main modes for these long trips (to the outside of their neighborhood) are motorized modes (2377 in Tehran and 2011 in Cairo). The respondents are categorized based on their main motorized modes in five categories, which are ridesourcing, private car, public bus/minibus/BRT/van, metro/light rail train/tram, and traditional taxi (formal or informal). Therefore, a categorical variable is defined as "main motorized mode" with these five categories for each respondent. The observed frequencies for each main motorized mode and the demographic profile are illustrated in Tables 1 and 2 for Tehran and Cairo.

The main purpose of this research is to study and compare the preference for walking to near destinations between the regular users of ridesourcing and other motorized modes. Therefore, the interviewees were asked whether they prefer to use vehicles for near destinations instead of walking. A binary variable is defined as the preference for using a vehicle instead of walking for a near destination (yes or no). Whereas, the previous question asked about the main motorized mode for trips outside the neighborhood, this question asks about the preference for using vehicles instead of walking to near destinations within the neighborhood. The reason is to avoid the endogeneity bias in the further analysis and regression model. Endogeneity bias might be caused by simultaneous causality when an independent variable is jointly determined with the dependent variable, and causal effects run reciprocally [35]. Therefore, the main motorized mode was asked for a trip outside the neighborhood as the explanatory variable, and the preference for not walking was asked for trips inside the neighborhoods as the dependent variable. Otherwise, if both variables were defined for the trips inside or outside the neighborhood, there would be a higher risk of endogeneity bias. 
Table 1. The demographic profile of frequent users of the motorized modes for trips outside their neighborhood in Tehran.

\begin{tabular}{|c|c|c|c|c|c|c|c|c|c|c|c|}
\hline \multirow{2}{*}{\multicolumn{2}{|c|}{$\begin{array}{c}\text { Tehran } \\
\text { Total } \mathbf{N}=2377\end{array}$}} & \multicolumn{2}{|c|}{ Public Bus N = 262} & \multicolumn{2}{|c|}{ Metro/Light Rail/Tram N = 222} & \multicolumn{2}{|c|}{ Personal/Household Car N = 1665} & \multicolumn{2}{|c|}{ Traditional Taxi N $=162$} & \multicolumn{2}{|c|}{ Ridesourcing N = 66} \\
\hline & & $\mathbf{N}$ & $\%$ & $\mathbf{N}$ & $\%$ & $\mathbf{N}$ & $\%$ & $\mathbf{N}$ & $\%$ & $\mathbf{N}$ & $\%$ \\
\hline \multirow{4}{*}{ Age } & $<25$ & 65 & 24.80 & 72 & 32.40 & 187 & 11.20 & 37 & 22.80 & 6 & 9.10 \\
\hline & $25 \leq$ Age $\leq 45$ & 114 & 43.50 & 93 & 41.90 & 1012 & 60.80 & 97 & 59.90 & 43 & 65.20 \\
\hline & $45<$ Age $\leq 60$ & 53 & 20.20 & 38 & 17.10 & 380 & 22.80 & 25 & 15.40 & 12 & 18.20 \\
\hline & $60<$ Age & 30 & 11.50 & 19 & 8.60 & 86 & 5.20 & 3 & 1.90 & 5 & 7.60 \\
\hline \multirow{2}{*}{ Gender } & Female & 160 & 61.10 & 121 & 54.50 & 792 & 47.60 & 91 & 56.20 & 40 & 60.60 \\
\hline & Male & 102 & 38.90 & 101 & 45.50 & 873 & 52.40 & 71 & 43.80 & 26 & 39.40 \\
\hline \multirow{2}{*}{ Activity Work or Study } & No & 142 & 54.20 & 98 & 44.10 & 421 & 25.30 & 49 & 30.20 & 27 & 40.90 \\
\hline & Yes & 120 & 45.80 & 124 & 55.90 & 1244 & 74.70 & 113 & 69.80 & 39 & 59.10 \\
\hline \multirow{2}{*}{ Having household car } & No & 96 & 36.60 & 84 & 37.80 & 0 & 0 & 21 & 13 & 0 & 0 \\
\hline & Yes & 166 & 63.40 & 138 & 62.20 & 1665 & 100 & 141 & 87 & 66 & 100 \\
\hline \multirow{2}{*}{ Having driving license } & No & 144 & 55.00 & 109 & 49.10 & 211 & 12.70 & 58 & 35.80 & 19 & 28.80 \\
\hline & Yes & 118 & 45.00 & 113 & 50.90 & 1454 & 87.30 & 104 & 64.20 & 47 & 71.20 \\
\hline \multirow{4}{*}{$\begin{array}{l}\text { Household income } \\
\text { Living cost } \\
\text { Income-cost ratio }\end{array}$} & & $\mathbf{M}$ & Mdn & $\mathbf{M}$ & Mdn & $\mathbf{M}$ & Mdn & $\mathbf{M}$ & Mdn & M & Mdn \\
\hline & Euro & 1002 & 935 & 1141 & 935 & 1435 & 1169 & 1275 & 1169 & 2165 & 1403 \\
\hline & Euro & 824 & 701 & 909 & 818 & 1151 & 1052 & 1064 & 1028 & 1344 & 1169 \\
\hline & & 1.32 & 1.09 & 1.26 & 1.12 & 1.28 & 1.17 & 1.22 & 1.14 & 1.57 & 1.17 \\
\hline
\end{tabular}

Table 2. The demographic profile of frequent users of the motorized modes to trips outside their neighborhood in Cairo.

\begin{tabular}{|c|c|c|c|c|c|c|c|c|c|c|c|}
\hline \multirow{2}{*}{\multicolumn{2}{|c|}{$\begin{array}{c}\text { Cairo } \\
\text { Total } \mathbf{N}=\mathbf{2 0 1 1}\end{array}$}} & \multicolumn{2}{|c|}{ Public Bus N = 789} & \multicolumn{2}{|c|}{ Metro/Light Rail/Tram N = 260} & \multicolumn{2}{|c|}{ Personal/Household Car N $=698$} & \multicolumn{2}{|c|}{ Traditional Taxi N $=150$} & \multicolumn{2}{|c|}{ Ridesourcing N = 114} \\
\hline & & $\mathbf{N}$ & $\%$ & $\mathbf{N}$ & $\%$ & $\mathbf{N}$ & $\%$ & $\mathbf{N}$ & $\%$ & $\mathbf{N}$ & $\%$ \\
\hline \multirow[t]{4}{*}{ Age } & $<25$ & 225 & 28.5 & 84 & 32.3 & 129 & 18.5 & 35 & 23.3 & 48 & 42.1 \\
\hline & $25 \leq$ Age $\leq 45$ & 422 & 53.5 & 119 & 45.8 & 389 & 55.7 & 62 & 41.3 & 58 & 50.9 \\
\hline & $45<$ Age $\leq 60$ & 114 & 14.4 & 43 & 16.5 & 148 & 21.2 & 40 & 26.7 & 8 & 7.0 \\
\hline & $60<$ Age & 28 & 3.5 & 14 & 5.4 & 32 & 4.6 & 13 & 8.7 & 0 & 0.0 \\
\hline \multirow{2}{*}{ Gender } & Female & 359 & 45.5 & 113 & 43.5 & 198 & 28.4 & 79 & 52.7 & 73 & 64.0 \\
\hline & Male & 430 & 54.5 & 147 & 56.5 & 500 & 71.6 & 71 & 47.3 & 41 & 36.0 \\
\hline \multirow{2}{*}{ Activity Work or Study } & No & 238 & 30.2 & 75 & 28.8 & 104 & 14.9 & 63 & 42.0 & 36 & 31.6 \\
\hline & Yes & 551 & 69.8 & 185 & 71.2 & 594 & 85.1 & 87 & 58.0 & 78 & 68.4 \\
\hline \multirow{2}{*}{ Having Household Car } & No & 432 & 54.8 & 175 & 67.3 & 0 & 0 & 49 & 32.7 & 0 & 0 \\
\hline & Yes & 357 & 45.2 & 85 & 32.7 & 698 & 100 & 101 & 67.3 & 114 & 100 \\
\hline \multirow{2}{*}{ Having driving license } & No & 619 & 78.5 & 206 & 79.2 & 84 & 12.0 & 107 & 71.3 & 84 & 73.7 \\
\hline & Yes & 170 & 21.5 & 54 & 20.8 & 614 & 88.0 & 43 & 28.7 & 30 & 26.3 \\
\hline \multirow{4}{*}{$\begin{array}{l}\text { Household income } \\
\text { Living Cost } \\
\text { Income-cost ratio }\end{array}$} & & M & Mdn & $\mathbf{M}$ & Mdn & $\mathbf{M}$ & Mdn & $\mathbf{M}$ & Mdn & $\mathbf{M}$ & Mdn \\
\hline & Euro & 5355 & 5000 & 4943 & 4600 & 9597 & 8000 & 6530 & 6000 & 11,362 & 9000 \\
\hline & Euro & 4960 & 4500 & 4510 & 4000 & 7692 & 7000 & 5765 & 5500 & 9298 & 8000 \\
\hline & & 1.10 & 1.00 & 1.09 & 1.00 & 1.22 & 1.10 & 1.14 & 1.00 & 1.18 & 1.11 \\
\hline
\end{tabular}

Note: $\mathrm{M}$ is Mean, and Mdn is Median. 


\subsection{Analysis Methods}

Regarding the research questions, a hypothesis is defined about the significant association between the variable of main motorized mode (including ridesourcing) and the preference for mode shift from walking to using vehicles in the samples of Cairo and Tehran. The Chi-square test of independence is applied to test this hypothesis by two-sided $p$-values at significance level 0.001 and a confidence level of $99 \%$. To measure the strength of association between nominal variables, we use Cramer's V, which indicates values from 0 for a weak association to 1 for a strong association between the variables. Moreover, the demographic parameters of the frequent ridesourcing users are compared with the other four motorized types to study the significant differences. We apply the Kolmogorov-Smirnov test to check the normal distribution of the following variables: age, monthly household income, and living cost. The test result for each of them indicates a $p$-value less than 0.001 , which means that they do not have a normal distribution. Therefore, the nonparametric tests like the median test and the Kruskal-Wallis test are applied to assess for significant differences of median and distribution on the mentioned continuous dependent variables by a categorical independent variable (main motorized mode) at significance level 0.05 . The null hypothesis for the Kruskal-Wallis test is the distribution of the given continuous variable, whether it is the same across categories of main motorized mode. The null hypothesis of the median test is the medians of the given variable, whether it is the same for different rider types. The results of the Kruskal-Wallis test reject the null hypothesis for monthly household income, cost, and household income/cost ratio in Cairo and Tehran at a 99\% confidence level. Moreover, the nonparametric median test indicates that medians of each mentioned continuous variables are significantly different across five regular users of motorized modes at 0.001 level $(p<0.001)$. The medians of the household incomes of regular ridesourcing users are 1403 (Euros) in Tehran and 9000 (Euros) in Cairo, which are higher than all other regular users of motorized modes in both cities. Also, the findings indicate that the regular ridesourcing users are a younger generation in Cairo.

The logistic regression approach is widely used for modeling transport behaviors. We apply binary logistic regressions to compare the probability of modal shift from walking to using vehicles between frequent users of ridesourcing and other motorized modes at confidence levels of $95 \%$. The odds of using a vehicle instead of walking are defined as the ratio between the probability of using a vehicle and the probability of walking for a near destination. The transformation from probability to odds is a monotonic transformation, meaning the odds increase as the probability increases or vice versa. In this regression model, the dependent variable is the odds of using a vehicle instead of walking. The categorical variable of main motorized mode is the independent variable, which categorizes the observations in mutually exclusive and collectively exhaustive groups.

As the main purpose of the model is to study the probability of modal shift among frequent users of motorized mode for the trips outside their neighborhoods, during the interviews, the respondents were asked to choose only one mode as their main motorized mode. The other independent variables are selected to control for possible confounding effects, as well as to avoid high multicollinearity among independent variables. Thus, the independent variables in the logistic regression are the main motorized mode, gender, household income-cost ratio, employment/study status, possession of a driving license, intersection density, link node ratio, frequency of work/study trips. Statistically, a correlation coefficient above 0.90 indicates high multicollinearity between independent variables [36,37]. Moreover, we applied the VIF test (variance inflation factor) to check the possibility of multicollinearity among independent variables. Hair et al. (2010) recommend that multicollinearity is a concern if VIF value is higher than 5 [37]. In the samples of both cities, the values of VIF are less than 4.0 for the mentioned independent variables, which indicate there is no problematic multicollinearity for this set of independent variables.

The Omnibus tests of model coefficients are used to check that the regression model for each city (with explanatory variables) is an improvement over the baseline model (without explanatory variables). It uses chi-square tests to see if there is a significant difference between the log-likelihoods of the baseline model and the new model. Here, the chi-square is highly significant for the model of Cairo 
and Tehran (chi-square $=466.304$ and 265.481) at 0.001 level, respectively. For regression models with a binary dependent variable, it is not possible to compute a single $\mathrm{R}^{2}$ statistic with all characteristics of $\mathrm{R}$ squared in the linear regression models. Therefore, Nagelkerke $\mathrm{R}$ squared is computed for each model of Cairo and Tehran. The results of the Omnibus test, the Nagelkerke R squared, and the correct overall prediction of the models are mentioned in Table 3 for the logistic models of Tehran and Cairo.

Table 3. The results of the Omnibus test and the goodness of fit for the models of Tehran and Cairo.

\begin{tabular}{ccc}
\hline Tests & Cairo & Tehran \\
\hline Omnibus Tests of Model Coefficients & & \\
Chi-square & 466.304 & 265.481 \\
$p$-value & $<0.001$ & $<0.001$ \\
-2 Log likelihood & 1773.064 & 2202.462 \\
Nagelkerke R Square & 0.309 & 0.180 \\
Overall percentage of correct prediction & $79.4 \%$ & $71.8 \%$ \\
\hline
\end{tabular}

\section{Results}

\subsection{The Association between the Main Motorized Mode and Preference for not Walking}

In order to test the association between the variables of main motorized mode for far destinations and the preference for using motorized mode instead of walking for near destinations, we apply the Chi-square test of independence for both cities. For Cairo, the null hypothesis is rejected, which indicates there is an association between main motorized mode and preference for not walking at 0.001 significance level with Pearson Chi-square $=369.01$ and Cramer's V $=0.428$. For Tehran, there is a significant association at 0.001 level with Pearson Chi-square $=119.15$ and Cramer's V $=0.224$ between the main motorized mode and using a vehicle instead of walking. The responses of regular motorized users to the question about whether they use a vehicle instead of walking, are shown in Figures 1 and 2.

Figure 1 shows that in Tehran, 19.7\% of regular ridesourcing users and 39.7\% of regular private car users prefer to use a motorized mode instead of walking. This percentage is lower for frequent public transport users, which are $17.6 \%$ for public buses and $13.5 \%$ for urban transit rails.

Figure 2 indicates that in Cairo, a higher percentage of regular ridesourcing users (19.3\%) prefer a modal shift from walking to motorized modes than regular users of public bus and metro/light rail with $11.2 \%$ and $8.1 \%$, respectively. However, they prefer to use vehicles instead of walking less than regular personal car users, which is $50 \%$.

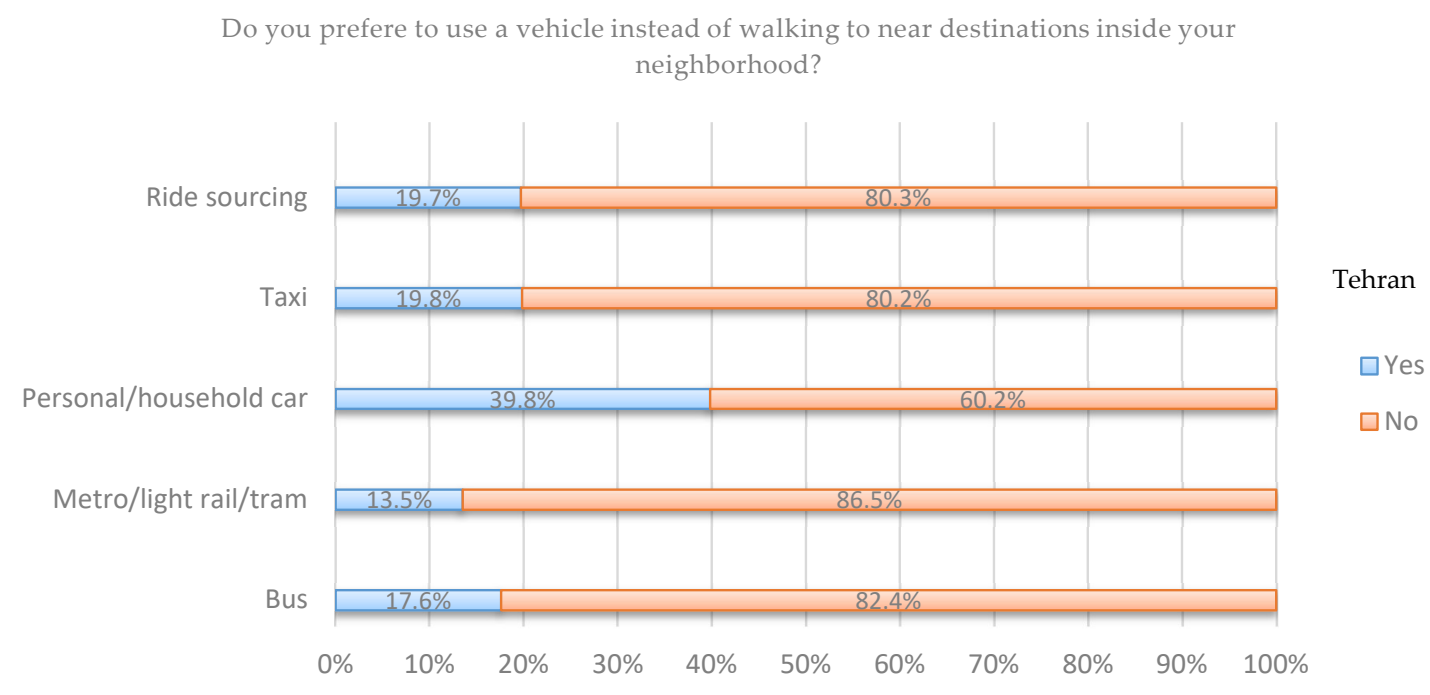

Figure 1. Preference for using a vehicle instead of walking to near destinations in Tehran. 


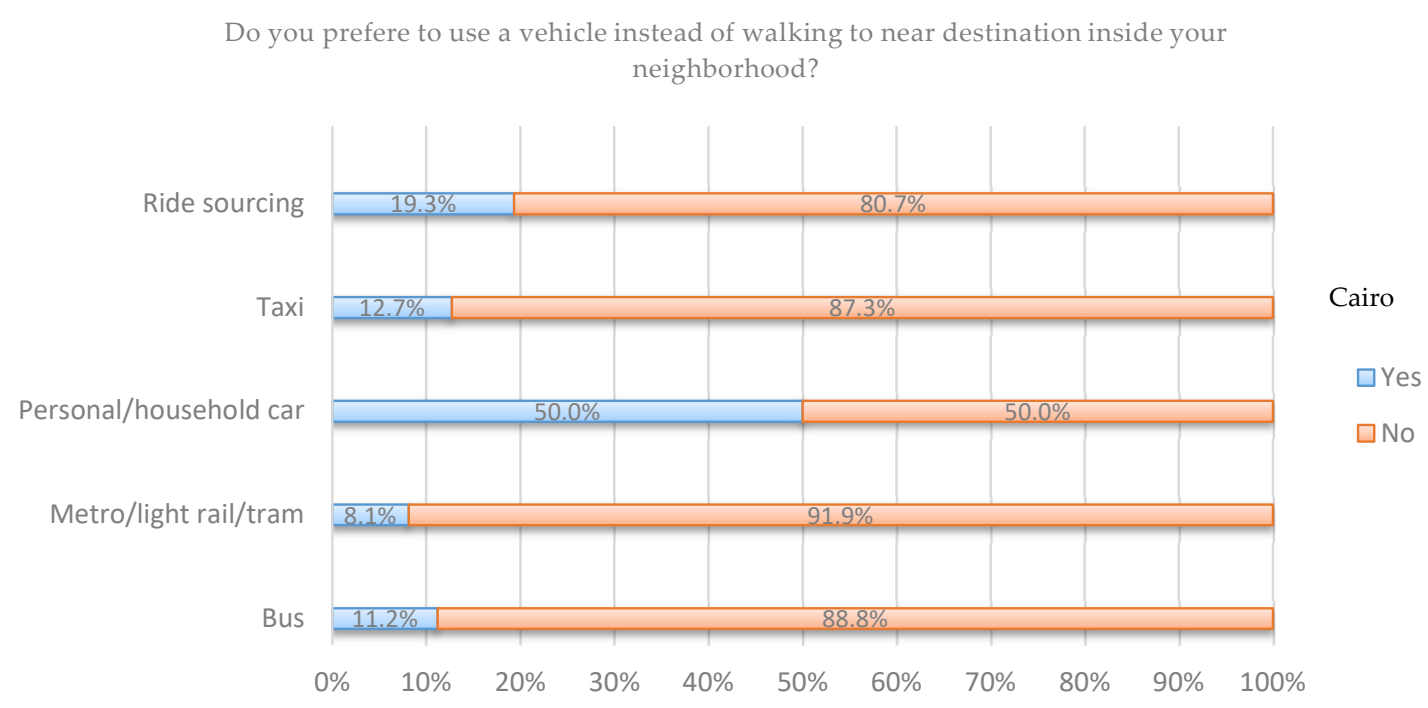

Figure 2. Preference for using a vehicle instead of walking to near destinations in Cairo.

\subsection{The Logistic Regression Models}

We used a binary logistic regression model to compare the odds of using motorized modes instead of walking for near destinations between regular users of ridesourcing and other motorized modes for each sample of Cairo and Tehran. The regular ridesourcing users are defined as the reference mode for the categorical variable of main motorized mode in the logistic regression. The results of these models for Cairo and Tehran are shown in Table 4. Each estimator helps to predict the probability of using motorized modes instead of walking. Each exponentiated coefficient is the odds ratio in the multiplicative scale for a unit increase in the related predictor holding other independent variables constant. An odds ratio greater than 1 specifies the odds of not walking by an increase of the independent variable.

The model for Tehran suggests four statistically significant variables at the 0.001 level, which are the main motorized mode, employment/study status, possession of a driving license, and the frequency of work/study trips per week. Furthermore, the variable of the monthly household income-cost ratio is significant at the 0.05 level. Because the variable of main motorized mode is a categorical variable, the significance of each category is tested relative to the reference category (ridesourcing), which indicates that regular use of personal/household car is significant with $p<0.001$, while the other types are not significant. Relative to the reference category (ridesourcing), the odds of using a vehicle instead of walking for the regular users of personal or household cars are 2.76 times greater than these odds for regular ridesourcing users. In other words, the odds of not walking for regular ridesourcing users $64 \%(1-1 / 2.76)$ are less than the regular car users. Therefore, the results indicate that the regular ridesourcing users are less likely to use motorized modes instead of walking for near destinations. However, the model indicates that there are no significantly different odds of not walking among regular ridesourcing users and public bus, metro, taxi. The model reveals that by holding other independent variables constant, the people who have work or are students have 4.12 times greater odds, and people who have a driving license have 2.74 greater odds of preference for replacing walking by car than the others. Each unit increase of monthly household income-cost ratio increases the odds of not walking by $14 \%$. The exponentiated coefficient of the number of work/study trip per week indicates that a unit increase reduces by $8 \%$ the odds of not walking. The odds ratios of the road network variables (link node ratio, intersection density) are not statistically significant in the Tehran model. 
Table 4. Binary logistic regressions in Tehran and Cairo.

\begin{tabular}{|c|c|c|c|c|c|c|c|c|c|}
\hline \multirow[t]{2}{*}{ City } & & \multicolumn{4}{|c|}{ Tehran } & \multicolumn{4}{|c|}{ Cairo } \\
\hline & & B & S.E. & $\begin{array}{l}p \text { value } \\
<0.001\end{array}$ & $\operatorname{Exp}(B)$ & B & S.E. & $\begin{array}{l}p \text { value } \\
<0.001\end{array}$ & $\operatorname{Exp}(B)$ \\
\hline Public bus & & 0.325 & 0.469 & 0.488 & 1.40 & -0.719 & 0.278 & 0.010 & 0.49 \\
\hline Metro/light rail & & -0.272 & 0.484 & 0.575 & 0.76 & -1.136 & 0.348 & 0.001 & 0.32 \\
\hline Personal/Household car & & 1.017 & 0.430 & 0.018 & 2.76 & 0.888 & 0.277 & 0.001 & 2.43 \\
\hline Taxi & & 0.403 & 0.482 & 0.403 & 1.50 & -0.457 & 0.356 & 0.199 & 0.63 \\
\hline Employee/student & Yes $=1$, No $=0$ & 1.417 & 0.192 & $<0.001$ & 4.12 & 0.923 & 0.177 & $<0.001$ & 2.52 \\
\hline Gender & Female $=1$, Male $=0$ & 0.148 & 0.105 & 0.159 & 1.16 & 0.307 & 0.141 & 0.029 & 1.36 \\
\hline Having a driver license & Yes $=1$, No $=0$ & 1.007 & 0.166 & $<0.001$ & 2.74 & 0.828 & 0.197 & $<0.001$ & 2.29 \\
\hline Household income/cost ratio & & 0.134 & 0.065 & 0.040 & 1.14 & 0.773 & 0.168 & $<0.001$ & 2.17 \\
\hline Freq work/study trip & No. per week & -0.081 & 0.011 & $<0.001$ & 0.92 & 0.003 & 0.009 & 0.777 & 1.00 \\
\hline Link node ratio & Percent of nodes/hectare & 0.008 & 0.004 & 0.052 & 1.00 & -0.037 & 0.006 & $<0.001$ & 0.96 \\
\hline Intersection density & nodes/hectare & 0.031 & 0.035 & 0.379 & 1.03 & -0.178 & 0.045 & $<0.001$ & 0.84 \\
\hline Constant & & -4.338 & 0.919 & $<0.001$ & 0.01 & 3.097 & 1.142 & 0.007 & 22.14 \\
\hline
\end{tabular}


The binary logistic model for Cairo includes seven statistically significant variables at the 0.05 level, which are the main motorized mode, gender, employment/study status, household income-cost ratio, possession of a driving license, intersection density, link node ratio. Relative to the reference category (ridesourcing), the odds of not walking for the regular car users are 2.43 times greater than ridesourcing. In other words, the odds of not walking for the regular ridesourcing users are $59 \%(1-1 / 2.43)$ lower than the frequent car users. However, the regular users of public bus and metro/light rail have lower odds of not walking than the ridesourcing users at $51 \%$ and $68 \%$. Therefore, the results indicate that the regular users of ridesourcing are more likely to use vehicles instead of walking than the public bus and metro/light rail. Moreover, there are no significantly different odds of not walking among regular ridesourcing users and traditional taxi users. The model reveals that female Cairenes have $36 \%$ higher odds of using vehicles instead of walking than males.

Moreover, by holding other variables constant, Cairenes, who have work or are students, have 2.52 times greater odds of not walking. The odds ratio of having a driving license is 2.29 in this model. Each unit increase of monthly household income-cost ratio increases the odds of not walking by $117 \%$. Each unit increase of the intersection density per hectare and link node ratio decrease around $4 \%$ and $16 \%$ the odds of not walking, respectively. Therefore, improving the connectivity of the neighborhoods by increasing the link node ratio and intersection density decreases the probability of a modal shift from walking in Cairo.

\subsection{Reasons for not Walking}

If the interviewees prefer to use motorized modes instead of walking for trips inside their neighborhood, they were asked about their main reason. For this question, the respondents could only choose one option as a major reason. The options were designed in the present form to collect subjective reasons related to the way people perceive and decide. This question gives an insight into the respondents' perceptions and attitudes and how they decide between motorized modes and walking for a near destination in their neighborhood. The options of this multichoice question were designed based on the review of similar studies in the context of the mobility behaviors in the MENA region [38-44]. The options include six reasons which are:

- The destinations are not near my living place;

- There are no attractive and beautiful routes;

- The streets are not safe;

- There are social and cultural problems in the spaces near my living place;

- I do not like walking;

- It is slow/takes too much time.

Figures 3 and 4 illustrate the main reasons per each user group of motorized mode. The finding indicates that the most observed reason of all user categories in both cities is "the destinations are not near my living places", for regular ridesourcing users make up $76.9 \%$ and $40.9 \%$ in Tehran and Cairo, respectively. In both cities, the regular ridesourcing users mentioned the three additional reasons for using a vehicle instead of walking, which are "there are no attractive and beautiful routes" (Tehran 7.7\%, Cairo 9.1\%), "the streets are not safe" (Tehran 7.7\%, Cairo 27.3\%), and "I do not like walking" Tehran $7.7 \%$, Cairo $22.7 \%$ ). The reason for social and cultural problems addresses social barriers for outside activities of women, discomforted at being observed in public spaces, or fearful of possible harassment. Figures 3 and 4 indicate that the regular ridesourcing users did not mention this reason for not walking in Tehran and Cairo. This survey included the subjective perception of other mobility modes, which were explained in another paper [45]. 
If you do not walk to destinations in your neighborhood and prefer to use a vehicle, what is the main reason?

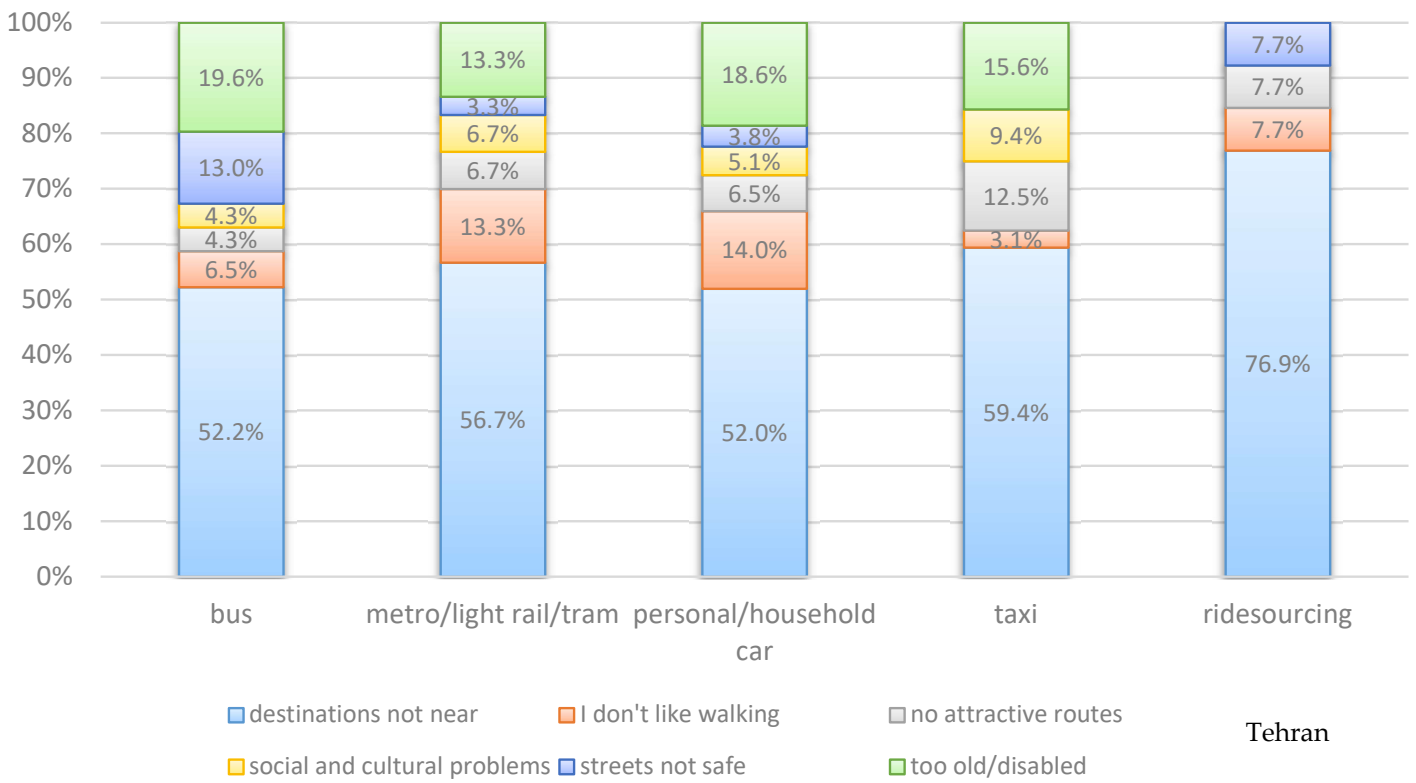

Figure 3. Reasons for frequent ridesourcing users for not walking in Tehran.

If you do not walk to destinations in your neighborhood and prefer to use a vehicle, what is the main reason?

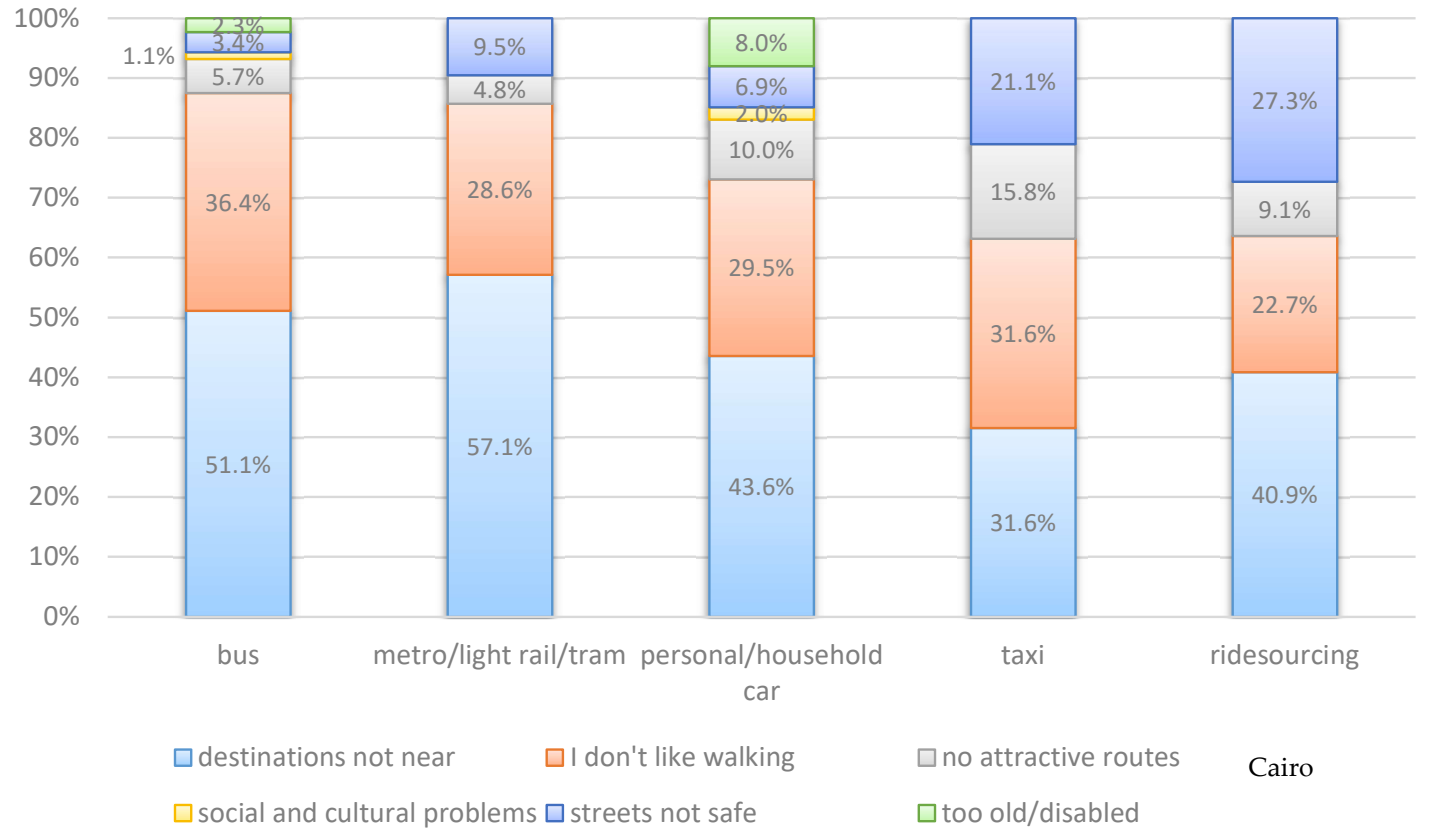

Figure 4. Reasons for frequent ridesourcing users for not walking in Cairo.

\section{Discussion}

The aim of this paper is to study the association between the regular use of ridesourcing and the preference for not walking to a near destination. The research method of this study is different from the previous researches in the West and the MENA context, which studied the impact of ridesourcing on other mode choices by some counterfactual questions $[4,21,23,46-48]$. They mostly 
asked, "what would you have done if ridesourcing services like Uber/Lyft had not been available?" If the respondents answered the nonmotorized modes, it was interpreted that they had a modal shift from nonmotorized modes to ridesourcing services. To answer this question, respondents have to think backwards, and imagine a supposedly manipulated past. Instead, this study first defines the different types of regular motorized modes based on their main modes for their trips outside their neighborhood. Then their current tendency to a modal shift from walking in a specific domain is derived by think-forward questions, such as "Do you prefer to use a vehicle instead of walking for a near destination inside the neighborhood?". In the first step of the analysis, the Chi-square test of independence indicates that there is a significant association between the main motorized mode for trips outside the neighborhood and the preference for not walking to near destinations inside the neighborhoods in both cities. In the next step, by binary logistic regression, the odds of preference for not walking are compared between regular users of ridesourcing and the other motorized modes, including public bus, metro/light rail, private car, and traditional taxi.

\subsection{Regular Use of Ridesourcing and Walking Mode Choice}

The results indicate that in Cairo for the same socioeconomic parameters (gender, work/study status, household income-cost ratios, frequency of work/study trip) and the same road network parameters of the neighborhood (link node ratio and intersection density), the regular users of ridesourcing are more likely to use a vehicle instead of walking for a near destination than regular users of public transports like public bus and metro/light rail. On the other hand, they are less likely to prefer modal shift from walking than regular car users. Therefore, the probability of not walking for regular users of ridesourcing in Cairo is between regular users of cars and public transport. In general, despite the studies which suggest that ridesourcing is substituting walking $[4,46,48]$ or indicate ridesourcing increases the use of nonmotorized modes for a small segment of users [49] our findings in Cairo indicate that the tendency of the regular ridesourcing users toward walking is between the regular users of public transports and private cars which is in the direction of the studies of Lee et al. [50].

However, the results of the Tehran model do not show significantly different odds of not walking between the regular users of ridesourcing and public transports users with the same socioeconomic and road network parameters. The results indicate that regular ridesourcing users are less likely to prefer using vehicles instead of walking than regular car users. This finding is in the same direction as Henao (2017) in Denver, indicating the ridesourcing users have more tendency to walking than ones who use more private cars [51]. For both cities, the models do not show a significant odds ratio for the regular users of taxis relatively to ridesourcing. Moreover, Figures 1 and 2 illustrate almost the same preference for walking between regular users of ridesourcing and taxi in both cities.

\subsection{Socioeconomic Factors}

The gender ratio of the regular ridesourcing users indicates that women are more frequent users than men in these two cities (60.6\% in Tehran and $64 \%$ in Cairo). This finding is confirmed by the other studies in the context of the MENA [52,53] and the African context [54]. Moreover, the findings show that regular ridesourcing users have remarkably higher household income than all other types of commuters in Tehran and Cairo. This finding is similar to other related studies in the West $[5,21,23,47,49,55]$. In addition, the car ownership comparison indicates that all regular ridesourcing users have at least one household car in the samples of both cities. Therefore, in the year of the survey (2017), the findings indicate that citizens in the low-income range and without a car were less likely to be regular users of ridesourcing in these cities. Based on the utility function of mobility modes, travel cost is one of the key factors which is related directly to the economic status of the household. If through the competition between local ridesourcing companies, the fares of ridesourcing decrease, then the average income of the regular ridesourcing users would decrease near to the average income of the non-car owner, which means they are more likely to become regular users. In 2018, there was a significantly fluctuating exchange rate between the Iranian currency and Euro. Therefore, 
these average results for income have changed in Tehran. However, because of the profitable market of ride hailing and the high penetration rate of $3 \mathrm{G}$ and $4 \mathrm{G}$ internet services and smartphones among the citizens in Tehran and Cairo, more local ridesourcing companies provide cheaper services. Therefore, it is expected that a higher percentage of non-car owners will adopt ridesourcing as their regular mode.

The age comparison between regular users of different motorized types indicates that in Cairo, the frequent ridesourcing users are remarkably younger $(42.1 \%$ under 25 years old $)$ than others. This finding is in the same direction as previous researches about the age of ridesourcing adopters in the context of Western countries $[4,22,23,56]$. However, in Tehran, the age distribution of frequent ridesourcing is almost the same as regular car users.

\subsection{Impact of Neighborhood Connectivity}

To study the association between the neighborhood connectivity factors and the preference for walking among regular motorized mode users, we selected two connectivity variables, which were link node ratio and intersection density. The binary logistic model of Cairo indicates that both variables have a significant odds ratio lower than 1, which are 0.96 and 0.84 for link node ratio and intersection density, respectively. This means that by increasing the connectivity of the neighborhoods, the regular motorized mode users are less likely to use a vehicle instead of walking to destinations inside their neighborhoods. This finding is in line with both the Western context [57-59] and the MENA context $[39,60,61]$, where it was concluded that improving the connectivity of neighborhoods substantially increases the tendency of citizens to walk. However, the odds ratios of these connectivity variables are not significant in the Tehran model. Thus, the Tehran model reveals that the probability of a modal shift from walking is more correlated with the socioeconomic variables of the regular users of motorized modes like household income-cost ratio, having a job or being students, and the possession of a driving license. This finding is in the line of some studies in the Western context [43], and in the MENA region $[38,44,62,63]$ indicating that socioeconomic factors have stronger effects than road network variables (like connectivity) on the preference for walking.

\subsection{Reasons for not Walking}

The percentage of regular ridesourcing users who do not like walking is around three times more in Cairo than Tehran, which indicates Cairene users have a more negative attitude towards walking than Tehranian regular users of ridesourcing. Moreover, Tehranian and Cairenes have a significantly different subjective perception of far distance to destinations inside their neighborhood. The perception of distance is influenced by not only the objective distance, but also the built environmental attributes, such as pedestrian infrastructure, quality of road network in the neighborhoods, as well as the lifestyle and cultural characteristics of the citizens. In addition, the subjective perceptions of safety in the streets play a more important role in the preference for not walking in Cairo than Tehran, particularly among regular ridesourcing users.

\section{Conclusions}

The results of the urban travel behavior research often come from high-income countries, while the developing countries and emerging markets have a tiny share. These findings are very much under the influence of the behaviors and preferences related to the regional context, and they are context-specific. With the rapidly growing share of online mobility services in the large MENA cities, there is a need to study their impacts on the mobility behavior of citizens. Moreover, the international ridesourcing companies are developing their services in the different countries of the global north and south region, like Uber and Careem. Therefore, the comparison of ridesourcing impacts between global north and south contexts gives international research institutes and companies an insight into the different mobility behaviors of ridesourcing users. This paper tried to shed light on the effects of ridesourcing adaptation on the tendency of walking for near destinations in the two cities of the MENA region. This study is based on the principle that regular use of one transport mode affects other mode choices. 
It showed that in Cairo and Tehran, the citizens who adopt ridesourcing as their regular motorized modes for their trips outside their neighborhood are less likely to use a vehicle instead of walking for near destinations than regular private car users. Therefore, these results indicate that car dependence of frequent ridesourcing users is significantly less than regular car users in both cities. However, in Cairo, they are more likely to replace walking by using a vehicle for trips inside the neighborhood than regular users of public bus and urban rail transits. Therefore, there is a concern that in Cairo, by shifting more regular public transport users to ridesourcing, the share of walking mode decreases in the modal split of Cairo. In addition, the findings showed that frequent users of ridesourcing have remarkably higher household incomes and higher car ownership rate in 2017 in both cities. However, the adoption of regular ridesourcing might be increased among lower-income households and non-household car owners by service fare decrease through the competition of ridesourcing companies, and improvement of internet services in the next years. Therefore, for further research, it is suggested to study the applicability and generalizability of these findings in these two cities in the following years and in other cities of the MENA region with a larger sample size.

As these cities need to improve their pedestrian infrastructures, the policy of imposing a special charge on ridesourcing fees, particularly for short distance-trips, could be useful to finance developing pedestrian infrastructure, as well as to avoid the modal shift from walking for near destinations. This policy has been implemented in some Western cities. Further research is suggested to study the feasibility and impacts of this policy in Tehran and Cairo. Moreover, the findings of this study indicate that regular users of ridesourcing have a significantly different subjective perception of far distance in these two cities. Further research is warranted to study this finding and the influence of built environmental attributes and cultural characteristics on the subjective perception of distance in Cairo and Tehran.

Author Contributions: Conceptualization, H.M.(Hamid Mostofi); Methodology, H.M. (Hamid Mostofi); Resources and Data, H.M. (Houshmand Masoumi); Formal analysis, H.M. (Hamid Mostofi), writing-original draft preparation, H.M. (Hamid Mostofi); writing-review and editing, H.M. (Hamid Mostofi), H.M. (Houshmand Masoumi) and H.-L.D. All authors have read and agreed to the published version of the manuscript.

Funding: This study was undertaken by the support of German Research Foundation (DGF) as the research project “Urban Travel Behavior in Large Cities of MENA Region (UTB-MENA) with the project number MA6412/3-1.

Acknowledgments: We acknowledge support by the German Research Foundation and the Open Access Publication Fund of TU Berlin.

Conflicts of Interest: The authors declare no conflict of interest. The funders had no role in the design of the study; in the collection, analyses, or interpretation of data; in the writing of the manuscript, or in the decision to publish the results.

\section{References}

1. Gössling, S. ICT and transport behaviour: A conceptual review. Int. J. Sustain. Trans. 2018, 12, $153-164$. [CrossRef]

2. Line, T.; Jain, J.; Lyons, G. The role of ICTs in everyday mobile lives. J. Trans. Geogr. 2011, 19, 1490-1499. [CrossRef]

3. Rayle, L.; Shaheen, S.; Chan, N.; Dai, D.; Cervero, R. App-Based, On-Demand Ride Services: Comparing Taxi and Ridesourcing Trips and User Characteristics in San Francisco University of California Transportation Center. 2014. UCTC-FR-2014 08. Available online: http://citeseerx.ist.psu.edu/viewdoc/download?doi=10.1. 1.662.707\&rep=rep1\&type $=$ pdf (accessed on 26 May 2020).

4. Rayle, L.; Dai, D.; Chan, N.; Cervero, R.; Shaheen, S. Just a better taxi? A survey-based comparison of taxis, transit, and ridesourcing services in San Francisco. Transp. Policy 2016, 45, 168-178. [CrossRef]

5. Taylor, B.D.; Chin, R.; Crotty, M.; Dill, J.; Hoel, L.A.; Manville, M.; Polzin, S.; Schaller, B.; Shaheen, S.; Sperling, D.; et al. Between Public and Private Mobility: Examining the Rise of Technology-Enabled transportation Services; Special Report 319; Transportation Research Board: Committee for Review of Innovative Urban Mobility Services: Washington, DC, USA, 2015. 
6. Rietveld, P. Biking and Walking: The Position of Non-Motorized Transport Modes in Transport Systems, Tinbergen Institute Discussion Papers 01-111/3; Tinbergen Institute: Amsterdam, The Netherlands, 2001.

7. Litman, T. Burwell Issues in sustainable transportation international. J. Glob. Environ. Issues 2006, 6, 331-347. [CrossRef]

8. Frank, L.; Schmid, T.; Sallis, J.; Chapman, J.; Selens, B. Linking objectively measured physical activity with objectively measured urban form. Am. J. Prev. Med. 2005, 28, 117-125. [CrossRef] [PubMed]

9. Frank, L.; Engelke, P. The Built Environment and Human Activity Patterns: Exploring the Impacts of Urban Form on Public Health. J. Plan. Literat. 2001, 16, 202-218. [CrossRef]

10. Doorley, R.; Pakrashi, V.; Ghosh, B. Quantifying the health impacts of active travel: Assessment of methodologies. Transp. Rev. 2015, 35, 1-24. [CrossRef]

11. Jarrett, J.; Woodcock, J.; Griffiths, U.K.; Chalabi, Z.; Edwards, P.; Roberts, I.; Haines, P. Effect of increasing active travel in urban England and Wales on costs to the National Health Service. Lancet 2012, 379, 2198. [CrossRef]

12. Mueller, N.; Rojas-Rueda, D.; Cole-Hunter, T.; Nazelle, A.; Dons, E.; Gerike, R.; Götschi, T.; Panis, L.; Kahlmeier, S.; Nieuwenhuijsen, M. Health impact assessment of active transportation: A systematic review. Prev. Med. 2015, 76, 103-114. [CrossRef]

13. SAE International, Taxonomy and definitions for terms related to shared mobility and enabling technologies. Available online: https://doi.org/10.4271/J3163_201809 (accessed on 21 June 2020).

14. Hamdi, N.; Mourad, M.; Knecht, E.; Potter, M. Egypt Passes Law Regulating Uber, Careem Ride-Sharing Services. Available online: https://www.reuters.com/article/us-egypt-uber/egypt-passes-law-regulatinguber-careem-ride-sharing-services-idUSKBN1I81VG (accessed on 7 May 2018).

15. Alkhalisi, Z.; Daftari, A. The Ride-Hailing App that Rules Tehran's Busy Streets. Available online: https: //money.cnn.com/2017/07/30/technology/iran-snapp-ride-hailing/ (accessed on 24 May 2020).

16. The Guardian. Snapp: How Tehran's Answer to Uber is Changing How People Travel, and Live. Available online: https://www.theguardian.com/cities/2017/jul/31/snapp-how-tehran-answer-to-uber-is-changinghow-people-travel-and-live (accessed on 24 May 2020).

17. Chan, N.D.; Shaheen, S. Ridesharing in North America: Past, Present, and Future. Transp. Revs. 2012, 32, 93-112. [CrossRef]

18. Firnkorn, J.; Müller, M. What Will Be the Environmental Effects of New Free-Floating Car-Sharing Systems? The Case of car2go in Ulm. Ecol. Econ. 2011, 70, 1519-1528. [CrossRef]

19. Martin, E.W.; Shaheen, S. Greenhouse Gas Emission Impacts of Carsharing in North America. IEEE Trans. Intellig. Transport. Syst. 2011, 12, 1074-1086. [CrossRef]

20. Elliot, M.; Susan, A.S.; Jeffrey, L. Impact of Carsharing on Household Vehicle Holdings: Results from North American Shared-Use Vehicle Survey. Transp. Res. Rec. 2010, 2143, 150-158. [CrossRef]

21. Feigon, S.; Murphy, C. Shared Mobility and the Transformation of Public Transit; TCRP Research Report; Transportation Research Board: Washington, DC, USA, 2016; p. 188. [CrossRef]

22. Circella, G.; Tiedeman, K.; Handy, S.; Alemi, F.; Mokhtarian, P. What Affects Millennials' Mobility? Part I: Investigating the Environmental Concerns, Lifestyles, Mobility-Related Attitudes and Adoption of Technology of Young Adults in California; National Center for Sustainable Transportation: Davis, CA, USA, 2016. Available online: https://escholarship.org/uc/item/6wm51523 (accessed on 24 May 2020).

23. Alemi, F.; Circella, G.; Handy, S.; Mokhtarian, P. What influences travelers to use Uber? Exploring the factors affecting the adoption of on-demand ride services in California. Travel Behav. Soc. 2018, 13, 88-104. [CrossRef]

24. Masoumi, H.; Fruth, E. Transferring Urban Mobility Studies in Tehran, Istanbul, and Cairo to Other Large MENA Cities: Steps toward Sustainable Transport. Urban Dev. Issues 2020, 65, 27-44. [CrossRef]

25. Bamberg, S.; Ajzen, I.; Schmidt, P. Choice of travel mode in the theory of planned behavior: The roles of past behavior, habit, and reasoned action. Basic Appl. Soc. Psychol. 2003, 25, 175-187. [CrossRef]

26. Masoumi, H.; Gouda, A.A.; Layritz, L.; Stendera, P.; Matta, C.; Tabbakh, H.; Fruth, E. Urban Travel Behavior in Large Cities of MENA Region: Survey Results of Cairo, Istanbul, and Tehran. Available online: https://www.researchgate.net/publication/326175506_Urban_Travel_Behavior_in_Large_Cities_of_ MENA_Region_Survey_Results_of_Cairo_Istanbul_and_Tehran (accessed on 24 May 2020).

27. Kitamura, R.; Mokhtarian, P.; Daidet, L. A micro-analysis of land use and travel in five neighborhoods in the San Francisco Bay Area. Transportation 1997, 24, 125-158. [CrossRef] 
28. Frank, L.; Bradley, M.; Kavage, S.; Chapman, J.; Lawton, T.K. Urban Form, Travel Time and Cost Relationships with Tour Complexity and Mode Choice. Transportation 2008, 35, 37-54. [CrossRef]

29. Bartholomew, K.; Ewing, R. Land Use-Transportation Scenarios and Future Vehicle Travel and Land Consumption: A Meta-Analysis. J. Am. Plan. Assoc. 2008, 75, 13-27. [CrossRef]

30. Kuzmyak, J.R.; Kockelman, K.; Bowman, J.; Bradle, M.; Lawton, K.; Pratt, R.H. Estimating Bicycling and Walking for Planning and Project Development; Task 3 Interim Report; No. 08-78; NCHRP Project: Washington, DC, USA, 2011.

31. Broach, J.; Dill, J.; Gliebe, J. Where do cyclists ride? A route choice model developed with revealed preference GPS data. Transp. Res. Part A Policy Pract. 2012, 46, 1730-1740. [CrossRef]

32. Krizek, K.J.; Forsyth, A.; Baum, L. Walking and Cycling International Literature Review. Final Report. 2009. Available online: https://pdfs.semanticscholar.org/e552/b9f029b5f03842854c43e092d10f7581654d.pdf (accessed on 21 June 2020).

33. Lamíquiz, P.J.; López-Domínguez, J. Effects of built environment on walking at the neighborhood scale. A new role for street networks by modeling their configurational accessibility? Transp. Res. 2015, 74, 148-163. [CrossRef]

34. Yehua, D.W.; Weiye, X.; Ming, W.; Ran, W. Walkability, Land Use and Physical Activity. Sustainability 2016, 8, 65. [CrossRef]

35. Wooldridge, J.M. Econometric Analysis of Cross Section and Panel Data; MIT Press: Cambridge, MA, USA, 2010.

36. Pallant, J. SPSS Survival Manual: A Step by Step Guide to Data Analysis Using SPSS, 4th ed.; Allen \& Unwin Book Publishers: Crows Nest, Australia, 2010.

37. Hair, J.F.; Black, W.C.; Babin, B.J.; Anderson, R.E.; Tatham, R.L. Multivariate Data Analysis, 7th ed.; Pearson: New York, NY, USA, 2010.

38. Etminani-Ghasrodashti, R.; Ardeshiri, M. Modeling travel behavior by the structural relationships between lifestyle, built environment and non-working trips. Transport. Res. Pol. Pract. 2015, 78, 506-518. [CrossRef]

39. Etminani-Ghasrodashti, R.; Ardeshiri, M. The impacts of built environment on home-based work and non-work trips: An empirical study from Iran. Transport. Res. Pol. Pract. 2016, 85, 196-207. [CrossRef]

40. Shahangian, R.; Kermanshah, M.; Mokhtarian, P.L. Gender differences in response to policies targeting commute to automobile-restricted central business district. J. Transp Res. Board. 2012, 2320, 80-89. [CrossRef]

41. Al-Atawi, A.; Saleh, W. Travel behavior in Saudi arabia and the role of social factors. Transport 2014, 29, 269-277. [CrossRef]

42. Danaf, M.; Abou-Zeid, M.; Kaysi, I. Modeling travel choices of students at a private, urban university: Insights and policy implications. Case Stud. Transport Pol. 2014, 2, 142-152. [CrossRef]

43. Handy, S.; Cao, X.; Mokhtarian, P. Correlation or Causality between the Built Environment and Travel Behavior? Evidence from Northern California. Transp. Res. Part D 2005, 10, 427-444. [CrossRef]

44. Soltani, A.; Esmaeili-Ivaki, Y. The Influence of Urban Physical Form on Trip Generation, Evidence from Metropolitan Shiraz, Iran. Indian J. Sci. Technol. 2011, 4, 1168-1174. [CrossRef]

45. Masoumi, H. A discrete choice analysis of transport mode choice causality and perceived barriers of sustainable mobility in the MENA region. Transp. Policy 2019, 79, 37-53. [CrossRef]

46. Hampshire, R.; Simek, C.; Fabusuyi, T.; Di, X.; Chen, X. Measuring the impact of an unanticipated suspension of ridesourcing in Austin, Texas. 2017. Available online: http://dx.doi.org/10.2139/ssrn.2977969 (accessed on 24 May 2020).

47. Clewlow, R.; Mishra, G. Disruptive Transportation: The Adoption, Utilization, and Impacts of Ride-Hailing in the United States. Institute of Transportation Studies, University of California, Davis, 2017, Research Report UCD-ITS-RR-17-07. Available online: https://itspubs.ucdavis.edu/wp-content/themes/ucdavis/pubs/ download_pdf.php?id=2752 (accessed on 24 May 2020).

48. Henao, A.; Marshall, W.E. The Impact of Ride-Hailing on Vehicle Miles Traveled. Transportation 2018. [CrossRef]

49. Circella, G.; Alemi, F. Transport Policy in the Era of Ride hailing and Other Disruptive Transportation Technologies. Advances in Transport Policy and Planning. 2018, pp. 119-144. Available online: http: //transp-or.epfl.ch/heart/2018/abstracts/5400.pdf (accessed on 28 May 2020).

50. Lee, K.; Qianran, J.; Animesh, A.; Ramaprasad, J. Are Ride-Hailing Services Sustainable? the Impact of Uber on the Transportation Mode Choices of Drivers, Riders, and Walkers. Riders Walkers 2019. [CrossRef] 
51. Henao, A. Impacts of Ride sourcing-Lyft and Uber-on Transportation Including VMT, Mode Replacement, Parking, and Travel Behavior. Ph.D. Thesis, Department of Civil and Environmental Engineering, University of Colorado at Denver, Denver, CO, USA, 2017.

52. Rizk, N.; Salem, N.; Weheba, N. A Gendered Analysis of Ridesharing: Perspectives from Cairo, CIPPEC publications, Egypt. 2018. Available online: http://www.cippec.org/wp-content/uploads/2018/09/ UrbanTransport-completo-web_CIPPEC.pdf (accessed on 21 May 2020).

53. IFC; Accenture; Uber. Driving Toward Equality: Women, Ride-Hailing and the Sharing Economy (Rep.). 2018. Available online: https://www.ifc.org/wps/wcm/connect/topics_ext_content/ifc_external_corporate_ site/gender+at+ifc/drivingtowardequality (accessed on 21 May 2020).

54. Dzisi, E.; Ackaah, W.; Aprimah, B.; Adjei, E. Understanding demographics of ridesourcing and the factors that underlie its use among young people. Sci. Afr. 2020, 7, e00288. [CrossRef]

55. Feigon, S.; Colin, M. Broadening Understanding of the Interplay Between Public Transit, Shared Mobility, and Personal Automobiles; Pre-publication draft of TCRP Research, 2018, Report 195; Transportation Research Board: Washington, DC, USA, 2018.

56. Conway, M.W.; Salon, D.; King, D.A. Trends in Taxi Use and the Advent of Ridehailing, 1995-2017: Evidence from the US National Household Travel Survey. Urban Sci. 2018, 2, 79. [CrossRef]

57. Ewing, R.; Cervero, R. Travel and the Built Environment: A Meta-Analysis. J. Am. Plan. Assoc. 2010, 76, 265-294. [CrossRef]

58. Reilly, M.K.; Landis, J. Influence of Urban form and Land Use on Mode Choice: Evidence from the 1996 Bay Area Travel Survey; TRB: Washington, DC, USA, 2002.

59. Cervero, R.; Radisch, C. Travel choices in pedestrian versus automobile oriented neighborhoods. Transp. Policy 1995, 3, 127-141. [CrossRef]

60. Shbeeb, L.; Awad, W. Walkability of School Surroundings and its Impacts on Pedestrian Behavior, TeMA. J. Land Use Mobil. Environ. 2013, 6, 171-188.

61. Özbil, A.; Argin, G.; Yesiltepe, D. Pedestrian route choice by elementary school students: The role of street network configuration and pedestrian quality attributes in walking to school. Int. J. Design Creat. Innov. 2016, 4, 67-84. [CrossRef]

62. Arabani, M.; Amani, B. Evaluating the Parameters Affecting Urban Trip-Generation. Iran. J. Sci. Technol. Trans. B Eng. 2007, 31, 547-560.

63. Soltani, A.; Shams, A. Analyzing the influence of neighborhood development pattern on modal choice. J. Adv. Transp. 2017, 2017. [CrossRef] 